\title{
Creep-fatigue interactions in equiaxed and single crystal Ni-base superalloys
}

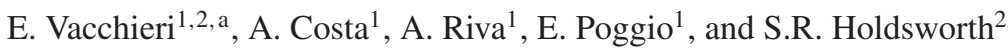 \\ ${ }^{1}$ Ansaldo Energia S.p.A., Corso Perrone 118, 16161 Genoa, Italy \\ 2 EMPA, Swiss Federal Laboratories for Materials Science and Technology, Überlandstrasse 129, 8600 Dübendorf, \\ Switzerland
}

\begin{abstract}
Ni-base superalloys are employed as structural materials for the most critical hot gas path components of gas turbines. The current market requirement is to cycle the machine every day, providing energy when it is most needed. It is therefore important to understand how creep and fatigue damages interact in these components. Starting from a significant knowledge base of mechanical and microstructural behaviour established from standard tests of the equiaxed and single crystal superalloys, creep-fatigue tests have been performed to evaluate how the two damage conditions develop together. The creep-fatigue testing conditions represent the maximum temperature and strain at the critical locations in real components, while the position of hold-time has been varied from tensile to compressive to understand the effect on reduction in crack initiation endurance with respect to standard LCF tests and on the microstructural mechanisms. The experimental test results have been explained in terms of microstructural evolution and they have been correlated to that observed at critical locations in real components.
\end{abstract}

\section{Introduction}

The consideration of creep-fatigue interaction is becoming more and more relevant in gas turbine critical components due to the higher operational flexibility and performance required by users. Gas turbine producers have to take into account this aspect during the design of new components and for the life assessment of existing parts. In fact, gas turbine operating profiles have changed in the last years from mainly base load to highly. The knowledge of material behaviour in the new operating regimes is a fundamental requirement for gas turbine producers.

Ni-base superalloys are mechanically strong materials that can support high mechanical stress at temperature close to their melting point. These alloys are used as structural materials of gas turbine components because they withstand strong thermal gradients due to their complex geometry, temperature distribution and intricate cooling system. The superior strength properties of this class of alloys come from the combined effects of precipitation hardening by a high volume fraction of ordered coherently embedded $\mathrm{Ni}_{3} \mathrm{Al} \gamma^{\prime}$ phase particles and the strong solid solution hardening of the $\gamma$ matrix. In fact, the great stability of the $\gamma / \gamma^{\prime}$ composite microstructure at high temperature and under the application of mechanical and thermal loading accounts for the outstanding performance of these materials in service $[1,2]$.

For these alloys, damage evolution is not "simply" related to the formation of physical damage features. Creep deformation can cause $\gamma^{\prime}$ phase rafting at high

\footnotetext{
${ }^{a}$ Corresponding author: erica.vacchieri@aen.ansaldo.it
}

temperatures and micro-twinning at lower temperatures, before the formation of physical damage, such as microvoids and cavities [2-9].

In the present paper the interaction between creep and fatigue has been studied for an equiaxed and a single crystal Ni-base superalloys. The creep-fatigue test conditions have been defined on the basis of the FE simulation of real components and the post-test inspections have been conducted to understand the physical mechanisms leading to damage development.

\section{Materials and methods}

The studied materials are two Ni based superalloys, one equiaxed, René 80, and one single crystal, PWA1483SX. These alloys are used for blades and vanes in industrial gas turbines. Their compositions are summarised in Table 1. The mechanical test samples were machined from cast test bars. For the SX alloy the test bars were solidified with a nominal $\langle 001\rangle$ orientation, having a $\theta$ acceptance limit as set for actual components. All the specimens were tested in the fully heat treated condition.

The starting microstructure for René 80 is composed of a bimodal distribution of $\gamma^{\prime}$ phase with a primary particle size of about $400 \mathrm{~nm}$ and secondary particles smaller than $20 \mathrm{~nm}$. The total $\gamma^{\prime}$ volume fraction is typically $50 \%$. PWA1483SX has a mono-modal distribution of $\gamma^{\prime}$ phase with a particle size of about $500 \mathrm{~nm}$ and a $\gamma^{\prime}$ volume fraction of about $60 \%$. In Fig. 1 two micrographs depict the microstructures of these two alloys.

An extensive characterisation campaign has been performed for both these materials in the past years,

This is an Open Access article distributed under the terms of the Creative Commons Attribution License 4.0, which permits unrestricted use, distribution, and reproduction in any medium, provided the original work is properly cited. 
Table 1. Chemical composition (wt \%) of the two superalloys.

\begin{tabular}{|l|l|l|l|l|l|l|l|l|l|l|l|}
\hline & \multicolumn{10}{|c|}{ Wt\% } \\
\hline Element & $\mathrm{Ni}$ & $\mathrm{Cr}$ & $\mathrm{Co}$ & $\mathrm{Al}$ & $\mathrm{Ti}$ & $\mathrm{W}$ & $\mathrm{Mo}$ & $\mathrm{Ta}$ & $\mathrm{C}$ & $\mathrm{Zr}$ & $\mathrm{B}$ \\
\hline René80 & $\mathrm{Bal}$ & 14.0 & 9.50 & 3.00 & 5.00 & 4.00 & 4.00 & - & 0.17 & 0.05 & 0.02 \\
\hline PWA1483SX & $\mathrm{Bal}$ & 12.2 & 9.00 & 3.60 & 4.08 & 3.80 & 1.90 & 5.00 & 0.07 & - & - \\
\hline
\end{tabular}
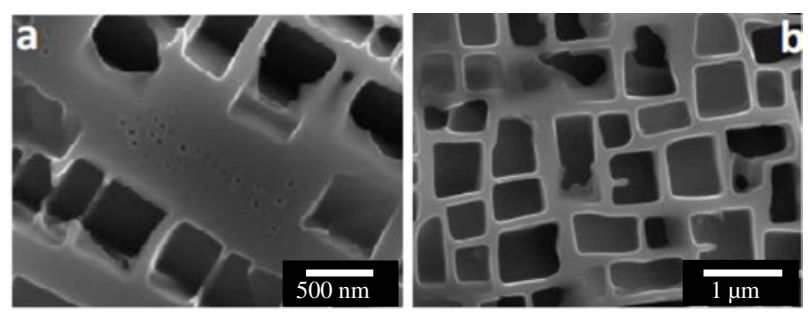

Figure 1. SEM micrograph of the as delivered $\gamma / \gamma^{\prime}$ microstructures of (a) René 80 and (b) PWA1483SX.

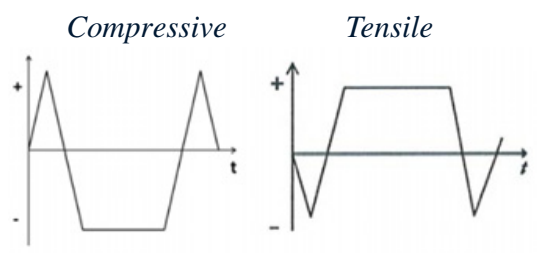

Figure 2. Schematic representation of the performed cyclic/hold tests.

involving creep and LCF tests. The mechanical responses were complemented by a comprehensive microstructural evaluation of the samples after test in order to correlate the microstructural features of the alloy to the damage evolution. This knowledge has been accumulated to develop the models necessary to represent creep and fatigue damage evolution, and also to understand the condition of material after service.

Creep-fatigue interaction was studied through isothermal cyclic/hold tests, whose conditions were defined from the FE simulation output and ex-service material evaluation of the critical locations in real GT components. The cyclic/hold tests were conducted in strain control mode at $850^{\circ} \mathrm{C}$ for René 80 and at $900^{\circ} \mathrm{C}$ for PWA1483SX. The hold time was 10 minutes and its position in the cycle was varied to study the effect of this parameter on fatigue endurance for both the alloys, as depicted in Fig. 2. The strain rate and the $\mathrm{R}\left(\varepsilon_{\min } / \varepsilon_{\max }\right)$ ratio were maintained constant $\left(10^{-2} \mathrm{~s}^{-1}\right.$ and $\left.\mathrm{R}=-1\right)$, while the strain range was chosen for both materials to be close to the one experienced by critical locations in real components. For both the materials, an equivalent LCF test (without hold time, in strain control mode and with the same strain range) was conducted with each cyclic/hold test to provide an appropriate reference for the evaluation of fatigue endurance reduction.

All the creep-fatigue samples were studied by classical and advanced microstructural examination techniques to characterise the damage mechanisms.
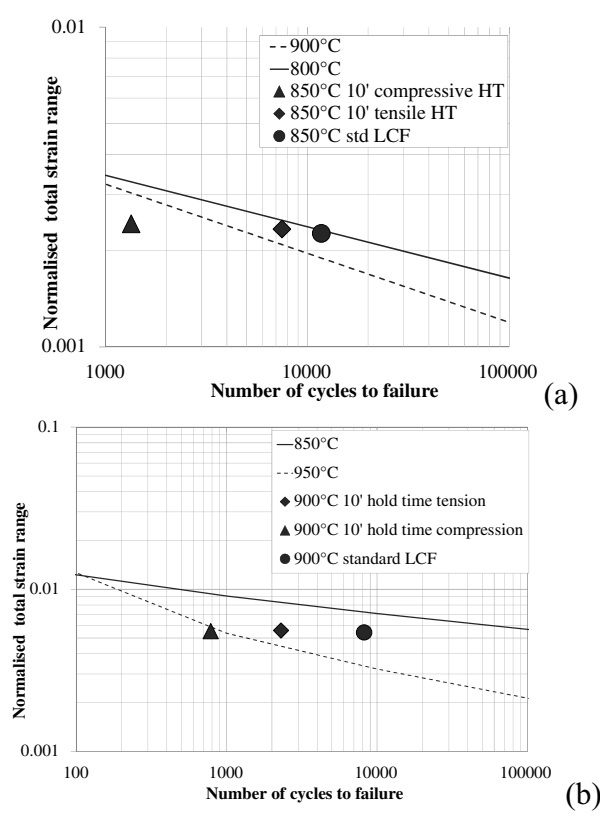

Figure 3. Cyclic/hold test results (a) for René 80 at $850^{\circ} \mathrm{C}$ compared with reference Manson-Coffin data lines for $800^{\circ} \mathrm{C}$ and $900{ }^{\circ} \mathrm{C}$, and (b) for PWA1483SX at $900^{\circ} \mathrm{C}$ compared with reference Manson-Coffin data lines for $850^{\circ} \mathrm{C}$ and $950^{\circ} \mathrm{C}$.

\section{Results and discussion}

The cyclic/hold test results are considered for the two materials in a single section, where they are compared and discussed. The next section then deals with the microstructural features of the specimens after test. Finally the creep-fatigue damage calculation results are examined and compared for both the alloys.

\subsection{Cyclic/hold test results}

The cyclic hold test results at $850^{\circ} \mathrm{C}$ for René 80 are summarised in Fig. 3a. The experimental test durations are compared to reference LCF endurance curves for $800^{\circ} \mathrm{C}$ and $900{ }^{\circ} \mathrm{C}$.

The same graph has been constructed for PWA1483SX, where the cyclic hold time tests at $900^{\circ} \mathrm{C}$ are compared with reference LCF endurance curves for $850^{\circ} \mathrm{C}$ and $950^{\circ} \mathrm{C}$ in Fig. 3b.

Both the alloys exhibit a significant reduction of endurance for the compressive hold time tests. The endurance reductions are represented as percentages in a histogram graph in Fig. 4. The endurance reductions have been calculated simply comparing the cyclic/hold time test duration to the standard LCF life at the same strain range and temperature (circle data points in Fig. 2). As it can be seen from this chart, the reduction of life is higher for 


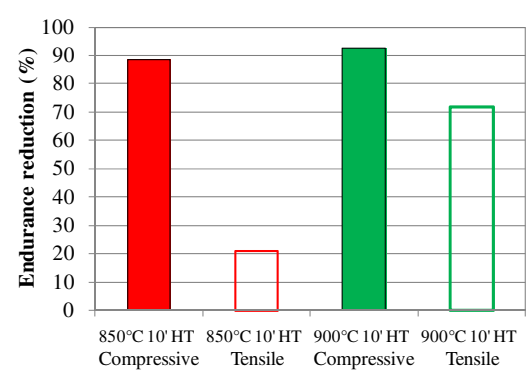

Figure 4. Endurance reduction comparison for the performed cyclic/hold tests for René 80 at $850^{\circ} \mathrm{C}$ (red bars) and PWA1483SX at $900^{\circ} \mathrm{C}$ (green bars) (calculated by comparing the test duration to the standard LCF life).

compressive hold time tests for both the materials, while tensile hold time tests exhibit a different life reduction for the two alloys. In particular, for René 80, the endurance reduction is smaller than for the SX alloy.

A possible explanation can be related to the lower testing temperature for René 80 coupons. In fact, $850^{\circ} \mathrm{C}$ for René 80 is the transition temperature between low (micro-twinning) and high temperature (rafting) creep deformation mechanisms [10], and it probably does not allow the development of significant creep damage in the microstructure to cause the same life reduction that is observed for the tensile hold time test of PWA1483SX.

However this observation does not provide a complete explanation for the compressive hold time test results since both the materials exhibit a very similar absolute reduction of fatigue endurance, even if they were tested at different temperatures (Fig. 4).

In part, the effect of hold time position on fatigue endurance can be explained by looking at the cyclic behaviour for the cyclic/hold time tests with respect to the standard LCF, as reported in Fig. 5.

René 80 and PWA1483SX cyclic/hold tests exhibit a shift of the mean stress with respect to the standard LCF tests performed at the same temperature and strain range. The mean stress moves towards positive values when the hold time is in compression and towards negative stresses for tensile hold times. Comparing the two materials, it is possible to note that for René 80 the shift continues during the whole test duration, while for PWA1483SX the mean stress value seems to stabilise at a relatively early fraction of life to a fixed value for the tests with compressive and tensile hold times.

The observed effect of hold time position (see Fig. 2) on fatigue endurance for René 80 is consistent with the published literature [11-13]. Significant cyclic/hold endurance reductions are observed for compressive hold times while a limited effect is noted for tensile hold times.

The explanation for this behaviour can be ascribed to the effect of mean stress. The strain range chosen for René 80 is mainly elastic so that the plastic contribution is very small or close to zero. In these circumstances, elastic deformation dominates and stress relaxation due to the presence of the hold time results in a shift of the cyclic stress-strain hysteresis loops.

Small cracks form early in fatigue life and the presence of a mean stress not equal to zero affects the local plastic

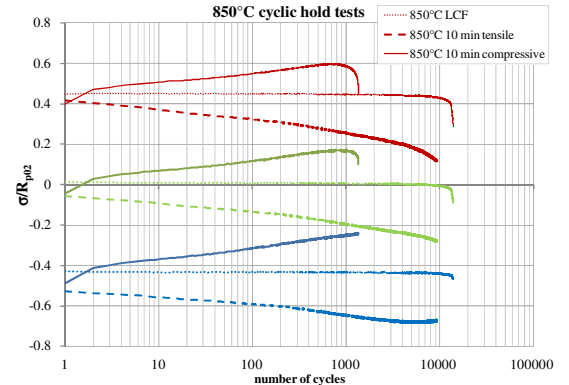

(a)

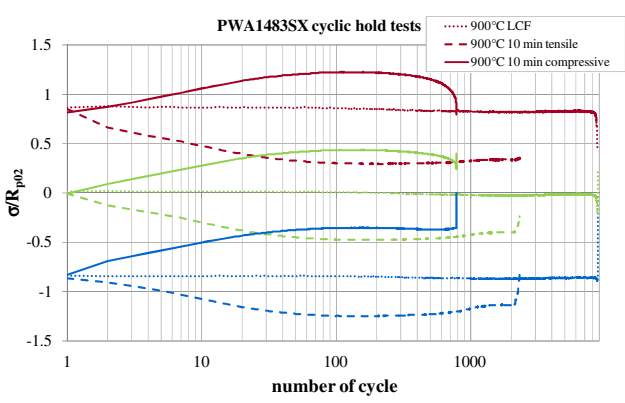

(b)

Figure 5. Normalised peak stresses (with respect to $\mathrm{R}_{\mathrm{p} 02}$ at the testing temperature and $10^{-2} \mathrm{~s}^{-1}$ ) for the cyclic/hold time tests (a) for René 80 , performed at $850^{\circ} \mathrm{C}$, and (b) for PWA1483SX, performed at $900^{\circ} \mathrm{C}$, compared to the standard LCF test (red $=$ maximum, green $=$ mean and light blue $=$ min stress).

strain at the crack tip during the early crack propagation phase. If a high compressive mean stress is acting (tensile hold time tests), it limits the opening of the cracks and decreases their tendency to grow. In contrast, if a high tensile mean stress is developed during the test, it causes a greater crack opening and an enhancement of crack growth rate.

The effect of hold time position (see Fig. 2) for PWA1483SX is slightly different, because in this case the adopted strain range is not purely elastic. Also in this case the compressive hold time test shows a shorter life with respect to the tensile hold time test. However the mean stress stabilises in the first cycles of the fatigue life and then remains constant during the test. This is probably due to the plastic strain contribution, and the fact that creep-fatigue can develop prematurely leading to a minor difference between fatigue endurance reductions for compressive and tensile hold time tests.

This behaviour is not common for steels, for which tensile hold times are typically more damaging than those in compression. Ni based superalloys have a much higher yield strength than most high temperature steels such that loading strains are predominantly elastic. In such circumstances, mean stress changes are not limited by reverse plasticity effects. Certain steels can exhibit lower cyclic/hold test endurances due to compressive hold times but this is more typically due to crack initiation in consequential surface oxide layers during subsequent transients into tension [14]. The contribution of oxidation should also be considered for $\mathrm{Ni}$ based superalloys as growing oxide layers can provide also a further source of crack initiation sites. 

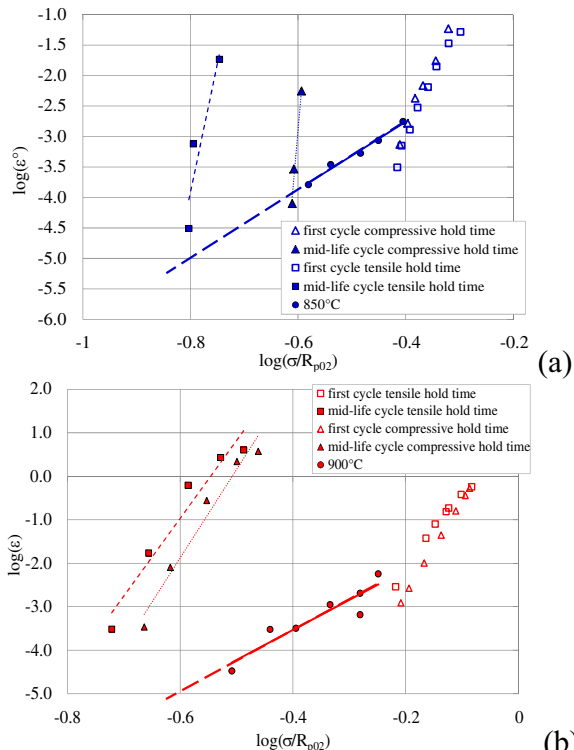

Figure 6. Norton plot of minimum creep rate and relaxation strain rate for the first and the mid-life cycle of the cyclic/hold time tests at the same temperature (triangle for compressive hold time, square for tensile): (a) René 80 at $850^{\circ} \mathrm{C}$ and (b) PWA1483SX at $900^{\circ} \mathrm{C}$.

Compressive hold time tests therefore exhibit higher endurance reduction for both materials because of a synergy between the mean stress and oxide-assisted crack initiation.

Stress relaxation response as part of the cyclic/hold tests has been studied in order to evaluate strain rate characteristics during the hold time and to understand if they change during the test due to the effects of fatigue on creep properties. In particular for the first and midlife cycle, the relaxation profiles were divided into small intervals and for each interval the stress relaxation rate was calculated. The instantaneous strain rates were then determined by conversion using the cyclic elastic modulus. Incremental first and mid-life cycle strain rates for the two cyclic/hold time tests are given in Norton diagrams for the two alloys. These are compared with the equivalent minimum creep rates from conventional creep tests at the same testing temperature for the two alloys in Fig. 6.

The cyclic stress relaxation responses of the two alloys are slightly different. For René 80 the softening influence of prior cycling at the start of relaxation is significantly greater in the tensile hold time test relative to the compressive hold time test. The softening effects diminish with increasing hold time to the point where the creep rates return to the cycle 1 level, on the extension of the $850^{\circ} \mathrm{C}$ Norton curve towards low stress values (see Fig. 6a). What changes dramatically is the slope of the strain rate for (stress) response of the mid-life cyclic tests compared with the measured values for the creep test. This $\dot{\varepsilon}(\sigma)$ characteristic is likely to be due to the short term influence of a small prior inelastic strain which is rapidly exhausted as is apparent in Figs. 6a and b, where the relaxation curves are depicted for first and mid-life cycles of the cyclic/hold time tests for René 80 . So the creep properties seem to be not greatly affected by the cyclic test
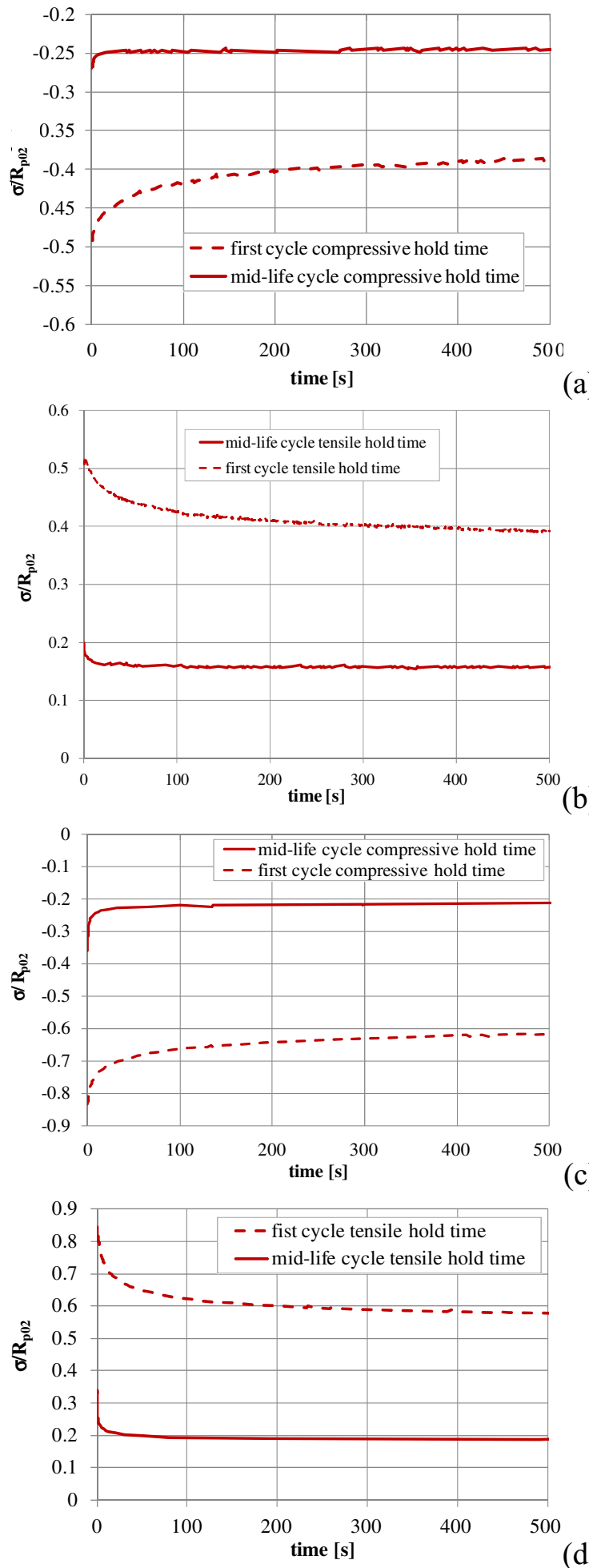

Figure 7. Relaxation phase for the first and mid-life cycle of the $(a, c)$ compressive and $(b, d)$ tensile hold time tests, $(a, b)$ for René 80, (c, d) for PWA1483SX.

in both the studied position of the hold time. A possible explanation can be ascribed to the purely elastic nature of the applied strain. The driving force for the observed endurance reduction for the compressive hold time tests can be attributed to the mean stress effect and oxideassisted crack initiation, as previously stated. 


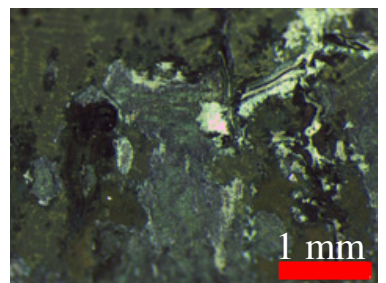

(a)

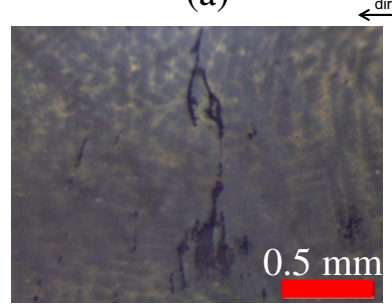

(c)

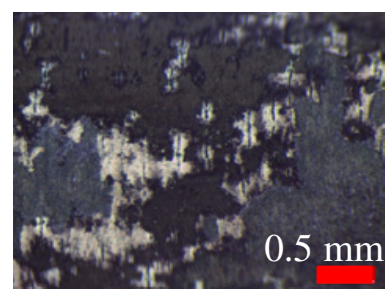

(b)

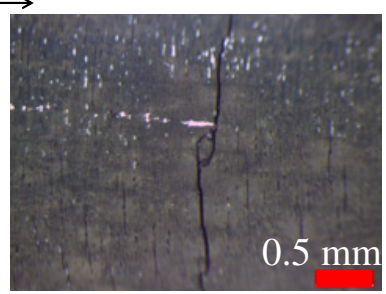

(d)

Figure 8. Stereo-microscope images of the external surface of (a and b) tensile and (c and d) compressive hold time tests for (a, c) René 80 and $(b, d)$ PWA1483SX.

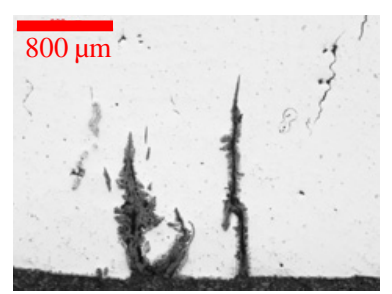

(a)

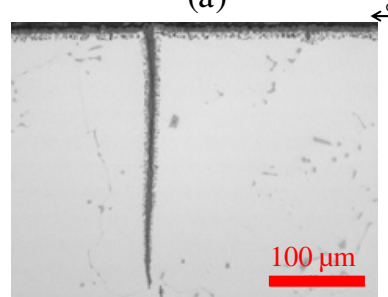

(c)

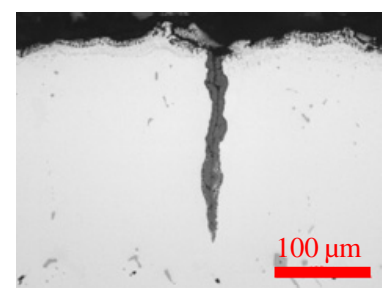

(b)

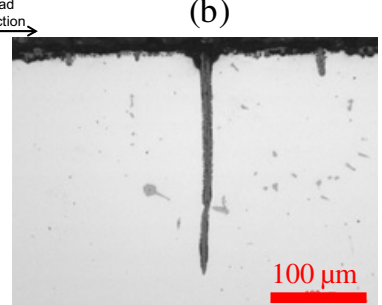

(d)

Figure 9. Optical microscope $(\mathrm{OM})$ micrographs of secondary cracks of ( $a$ and $b$ ) tensile and ( $c$ and d) compressive hold time tests for (a, c) René 80 and (b, d) PWA1483SX.

For PWA1483SX the situation is "less" complex because the softening influence of prior cycling at the start of relaxation is similar for both hold time conditions (tensile and compressive), with the tensile hold time test exhibiting slightly more softening than the compressive hold time test. For these tests the softening effects decrease but still remain with increasing hold time, as creep rates do not return to cycle 1 levels. The persistency of the softening effects for both the cyclic/hold time tests can be ascribed to the effect of prior cyclic plasticity on the creep properties of the material. Relaxation rates during mid-life cycle hold times in compression and tension are low for both materials, but with the rates being discernibly higher for PWA1483SX (Figs. 7c and d) relative to René 80 (Figs. 7a and b).

The results obtained for the strain rates of the cyclic/hold time tests are consistent with the endurance reductions observed for the two alloys. The SX alloy shows

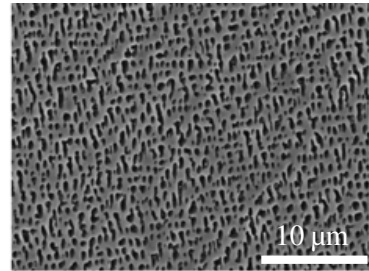

(a)

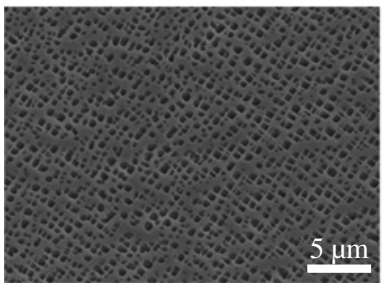

(c)

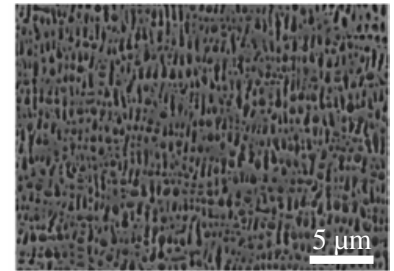

(b)

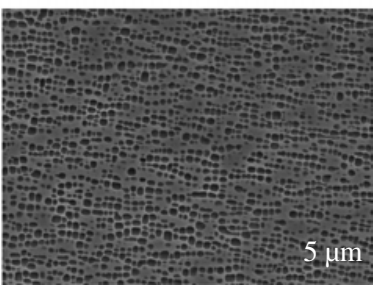

(d)
Figure 10. SEM microscope micrographs of $\gamma / \gamma^{\prime}$ phase microstructure in the gauge length of the (a and b) tensile and (c and d) compressive hold time tests for (a, c) René 80 and (b, d) PWA1483SX.

a significant reduction of fatigue life for compressive and tensile hold times, while for René 80 a significant fatigue endurance reduction is observed only in the compressive hold time test and not for the tensile hold time condition.

\subsection{Microstructural damage characterisation}

The cyclic/hold test coupons for both alloys exhibit different features in terms of their physical damage conditions with respect to the different hold time positions.

Starting from the external surface of the samples after test (Fig. 8), several secondary cracks are observed in the tensile hold time coupons for both the alloys. The main difference between the equiaxed and single crystal materials is that the cracks in René 80 samples are larger and more irregular in their path, not exactly normal to the loading direction and following the grain boundaries. For the SX alloy the cracks for the tensile hold time condition are very small, they seem superficial and all of them are normal to the loading direction. The compressive hold time test coupons, instead, depict few secondary cracks, very sharp and thin, normal to the loading direction for both the alloys, with some irregularities for the René 80 samples due to the equiaxed solidification.

The longitudinal sections of the samples confirm the surface observations (Fig. 9):

o the compressive hold time test condition is responsible for sharp and straight cracks, transgranular for René 80 , that propagate perpendicularly to the loading direction.

o the tensile hold time test condition for René 80 is responsible for several penetrating secondary cracks that propagate in a mixed transgranular/ intergranular mode, and for creep damage at the grain boundaries. For the SX alloy, secondary cracks penetrate similarly as for the compressive hold time condition, but they are larger and their edges are wavy and irregular with respect to the compressive condition. 
Finally, the $\gamma / \gamma^{\prime}$ phase microstructures in the tensile hold test samples of both the materials exhibit a first indication of $\gamma^{\prime}$ rafting, normal to the loading direction. For René 80 the direction is not exactly normal due to the orientation of the captured solidification grain with respect to the loading direction (Fig. 10a). The $\gamma^{\prime}$ phase rafting confirms the creep deformation acting on the samples, also for the SX alloy where creep physical damage was not observed (Fig. 10b). In fact, for this class of alloys the creep damage depicts itself in the form of microstructural modification of $\gamma^{\prime}$ phase $[1,2,7]$. For the compressive hold time condition, the $\gamma / \gamma^{\prime}$ phase microstructure is not modified by the tests apart from a slight rounding of the $\gamma^{\prime}$ phase cube edges that characterises mainly the microstructure observed in the SX sample (Figs. 10c and d).

\section{Conclusions}

Creep-fatigue interaction has been studied for two $\mathrm{Ni}$ based superalloys, one equiaxed and one single crystal, employed in critical vanes and blades of industrial gas turbines. Test parameters were adopted to simulate critical location conditions of real components, in terms of stressstrain state and maximum temperature.

The fatigue endurance reductions observed for different hold time positions for the two alloys have been discussed from different points of view and a possible explanation has been proposed. If the applied strain is purely elastic, the reduction of endurance is driven by the mean stress effect and oxide-assisted crack initiation. If a small amount of plastic strain contributes to the total strain range, the mean stress stabilises early in sample life and acts together with creep deformation, enhanced by prior cyclic plasticity. The reduction of endurance in this case is significant for both cyclic/hold time test conditions, and the slightly shorter life for compressive hold time tests is explained by the mean stress effect and oxide-assisted crack initiation.
The microstructural investigations confirm that the presence of creep damage in the tensile hold time tests seems to act independently from fatigue damage, while this is not true for creep deformation, at the level of $\gamma / \gamma^{\prime}$ phase microstructure, that affects the test endurances. However, it was not possible to highlight the differences between the two material conditions in terms of plastic strain on compressive hold time test duration. In fact, for these tests, the microstructural observations highlight the oxide-assisted crack initiation. Further EBSD analyses are planned to be done in order to compare and quantify the local plastic strain for different testing conditions.

\section{References}

[1] R.C. Reed, The superalloys, fundamentals and applications, Cambridge University Press (Cambridge, 2006), pp. 33-120, 121-216

[2] H. Mughrabi, Mat. Sci. Techn. 25, 2 (2009)

[3] J.J. Moverare, Mat. Sci. Eng. A 528, 13-14 (2011)

[4] J.J. Moverare et al., Proc. Eng. 10 (2011)

[5] M Segersäll et al., Superalloys 2012 (2012), pp. 215223

[6] J.J. Moverare et al., Superalloys 2012 (2012), pp. 369-377

[7] J.X. Zhang et al., Scripta Mat. 54, 4 (2006)

[8] J.X. Zhang et al., Acta Mat. 56, 13 (2008)

[9] J.X. Zhang et al., Scripta Mat. 61, 12 (2009)

[10] E. Vacchieri, A. Costa, Superalloys 2012 (2012), pp. 235-244

[11] D.C. Lord, L.F. Coffin, Jr, Met. Trans. 4 (1973)

[12] W.J. Plumbridge, E.G. Ellison, Mat. Sci. Tech. 3 (1987)

[13] L.J. Chen et al., Int. J. Fat. 20, 7 (1998)

[14] B. Fournier, M. Sauzay, C. Caës, M. Noblecourt, M. Mottot, A. Bougault, V. Rabeau, J. Man, O. Gillia, P. Lemoine and A. Pineau, Int: J. Fat. 3 (2008) 